\title{
Inflammatory root resorption in primary molars: prevalence and associated factors
}

\section{Raquel Gonçalves Vieira- Andrade ${ }^{(a)}$ Clarissa Lopes Drumond(b) Laura Pereira Azevedo Alves ${ }^{(b)}$ Leandro Silva Marques(c) Maria Letícia Ramos-Jorge(b)}

(a) Department of Orthodontics and Pediatric Dentistry, School of Dentistry, Federal University of Minas Gerais - UFMG, Belo Horizonte, MG, Brazil.

(b) Department of Pediatric Dentistry, School of Dentistry, Federal University of the Jequitinhonha and Mucuri Valleys, Diamantina, MG, Brazil.

(c) Department of Orthodontics, School of Dentistry, University of Rio Verde Valley UNINCOR, Três Corações, MG, Brazil.

Declaration of Interests: The authors certify that they have no commercial or associative interest that represents a conflict of interest in connection with the manuscript.

Corresponding Author:

Raquel Gonçalves Vieira-Andrade

E-mail: raquelvieira.andrade@gmail.com

Received for publication on Feb 09, 2012 Accepted for publication on May 10, 2012

\begin{abstract}
This study aimed at determining the prevalence of inflammatory root resorption and associated factors in 1068 primary mandibular molars in 453 children 3 to 12 years of age. Age, dental history and medical history were recorded using a questionnaire administered to the children's parents/caregivers. Previously trained and calibrated examiners assessed radiographic images of the primary molars by direct observation, with the aid of a viewing box. Root resorption (physiological or inflammatory), dental crown status (healthy, carious with no pulp involvement, carious with pulp involvement and evidence of restoration), and pulpotomy or pulpectomy were determined. Data analysis involved descriptive statistics, the chi-square test and a multiple logistic regression $(\mathrm{p}<0.05)$. The prevalence of inflammatory root resorption was $16.2 \%(\mathrm{n}=173)$. The male gender (OR: 1.4; 95\% CI), the 3-to-7-years age bracket (OR: $1.5 ; 95 \% \mathrm{CI}$ ), an unhealthy dental crown (OR: $8.7 ; 95 \% \mathrm{CI})$, caries with pulp involvement (OR: 7.4; 95\% CI), pulpotomy (OR: 3.1; 95\% CI), and pulpectomy (OR: $5.4 ; 95 \% \mathrm{CI}$ ) were risk factors for the occurrence of inflammatory root resorption in primary molars. In conclusion, the prevalence of inflammatory root resorption in the present sample was $16.2 \%$. Gender, age, an unhealthy tooth, caries with pulp involvement, pulpotomy, pulpectomy, and the absence of a restoration were associated with a higher occurrence of inflammatory root resorption in primary molars.
\end{abstract}

Descriptors: Root Resorption; Prevalence; Epidemiology.

\section{Introduction}

Inflammatory root resorption in primary teeth is a frequent finding in the clinical practice of pediatric dentists. ${ }^{1}$ Radiographically, inflammatory root resorption is characterized by the gradual loss of tooth substance associated with persistent, progressive radiolucency of the adjacent alveolar bone. ${ }^{2,3}$ This leads to an imbalance in the stomatognathic system and problems such as unerupted permanent successors and the early loss of primary teeth. ${ }^{1,3-10}$

Inflammatory root resorption is generally diagnosed by clinical and radiological examinations, especially periapical radiographs. ${ }^{11,12}$ This type of resorption is a consequence and/or complication of different clinical situations, such as pulp, periodontal and/or periradicular infectious processes, dental injury, orthodontic forces, or excessive occlusal forces. ${ }^{1,6}$

Anatomical aspects peculiar to the primary teeth, such as reduced 
enamel and dentin thickness, greater permeability and lower hardness and strength, further contribute to the more rapid spread of infectious processes in the pulp tissue, which can trigger an inflammatory process and root resorption. ${ }^{13,14}$ Treatment consists of removing the triggering factors, whose determination is critical to choosing the most appropriate protocol. ${ }^{9}$

Although studies in the literature report the prevalence of and factors associated with the development of inflammatory resorption in permanent teeth, little is known about how these factors influence the occurrence of inflammatory resorption in primary teeth. ${ }^{3,15}$ Since the occurrence of this type of resorption is highly frequent in the clinical practice of pediatric dentists, the study of this phenomenon is of considerable importance to the diagnosis and planning of dental care for children.

This study was conducted to determine the prevalence of inflammatory pathological root resorption, and associated factors, in the primary mandibular molars of children 3 to 12 years of age, based on radiographic images and clinical records.

\section{Methodology}

A retrospective cross-sectional study was carried out on a sample of 1068 primary mandibular molars assessed on 671 periapical radiographs retrieved from the radiographic files of the pediatric clinic at the Federal University of the Jequitinhonha and Mucuri Valleys (Brazil). The periapical radiographs were taken with four identical x-ray machines (Dabi Atlante, Ribeirão Preto, Brazil) and processed manually. Only high-quality periapical radiographs (with adequate details, good sharpness, density and contrast, and no distortions) exhibiting the root apex of primary mandibular molars and the tooth bud of the permanent successor were used. The radiographs were obtained from 453 male and female children 3 to 12 years of age, from the city of Diamantina, state of Minas Gerais, Brazil.

The research team was composed of four examiners who underwent a training program and calibration process involving 80 randomly selected radiographic images of primary mandibular molars, either involved in an inflammatory process or not.
These images were not part of the main study. Seven days following the initial evaluation, the same 80 radiographs were re-evaluated by the examiners to determine intraexaminer agreement (kappa index). The examiners' results were compared to those of a doctoral student with expertise on the subject, considered the gold standard. Kappa values ranged from 0.82 to 0.91 . Diagnostic differences were discussed and resolved by consensus.

A questionnaire was previously administered to the children's parents/caregivers to acquire baseline data on gender, age, dental history and medical history. Medical history involved the presence/absence of general health problems, such as systemic and chronic diseases. Dental history was taken to gain information on treatments performed on the teeth under study.

The periapical radiographs were analyzed by the researchers by direct observation, with the aid of a viewing box (CARP, Ribeirão Preto, Brazil). This assessment was divided into two phases. The researchers first determined the type of root resorption (physiological or inflammatory). Inflammatory root resorption was defined as the presence of a periapical lesion radiographically characterized by radiolucency of the adjacent alveolar bone, associated with the loss of tooth substance. The researchers then determined the dental crown status (healthy, carious with no pulp involvement or carious with pulp involvement). The researchers also checked whether the primary molar showed any evidence of restoration, pulpotomy or pulpectomy, which was confirmed by examining the patient's records.

\section{Statistical analysis}

The data were analyzed using the Statistical Package for Social Sciences (SPSS for Windows, version 17.0, SPSS Inc., Chicago, USA). Descriptive analysis (absolute and relative frequencies) was performed for all variables. The chi-square test was used to determine any association between an inflammatory root resorption and each independent variable (gender, age, general health problem, healthy tooth, caries with no pulp involvement, caries with pulp involvement, presence of a restoration, pulpotomy and pulpectomy). The significance level 
was set at $5 \%(\mathrm{p}<0.05)$. All independent variables with a $\mathrm{p}$-value $\leq 0.20$ were included in a multivariate logistic regression model.

The present study received the approval of the Institutional Review Board of the Federal University of the Jequitinhonha and Mucuri Valleys (Brazil) under protocol number 135/10.

\section{Results}

A total of 1068 primary mandibular molars were assessed from 453 children (mean age: 7.9 years; standard deviation: 2.12 years), $54.4 \%(\mathrm{n}=252$ ) of whom were male and $45.6 \%(\mathrm{n}=211)$ were female. The prevalence of inflammatory root resorption was $16.2 \%(\mathrm{n}=173)$. Statistically significant associations were found between inflammatory root resorption and gender $(\mathrm{p}<0.05)$, age $(\mathrm{p}<0.05)$, an unhealthy tooth $(\mathrm{p}<0.001)$, caries with pulp involvement $(\mathrm{p}<0.001)$, a restored tooth $(\mathrm{p}<0.001)$, pulpotomy $(\mathrm{p}<0.001)$ and pulpectomy $(\mathrm{p}<0.001)$ (Table 1$)$. No statistically significant association was found between inflammatory root resorption and general health problems or caries with no pulp involvement.

Table 2 shows the results of the multivariate logistic regression analysis. The following variables were risk factors for inflammatory root resorption in primary mandibular molars: male gender (OR: 1.4; 95\% CI), 3-to-7-years age bracket (OR: 1.5; 95\% CI), an unhealthy tooth (OR: $8.7 ; 95 \% \mathrm{CI}$ ), caries with pulp involvement (OR: 7.4; 95\% CI), absence of a restoration (OR: 3.1; 95\% CI), pulpotomy (OR: 3.1; 95\% CI) and pulpectomy (OR: 5.4; 95\% CI).

\section{Discussion}

In the present study, inflammatory root resorption was associated with gender, age, an unhealthy tooth, caries with pulp involvement, pulpotomy, pulpectomy and absence of a restoration. This diversity of clinical situations corroborates the findings of a previous study, defining inflammatory resorption as a complication and/or consequence of different clinical situations, such as pulp, periodontal and/or periradicular infectious processes. ${ }^{1}$

A statistically significant association was found between inflammatory root resorption and age
Table 1 - Associations between independent variables and inflammatory root resorption.

\begin{tabular}{|c|c|c|c|c|}
\hline \multicolumn{5}{|c|}{ Inflammatory root resorption } \\
\hline & $\begin{array}{c}\text { Absent } \\
\text { n (\%) }\end{array}$ & $\begin{array}{c}\text { Present } \\
\mathrm{n}(\%)\end{array}$ & $\begin{array}{l}\text { Total } \\
\text { n (\%) }\end{array}$ & $p^{*}$ \\
\hline \multicolumn{5}{|c|}{ Gender } \\
\hline Male & $479(81.7)$ & $107(18.3)$ & $586(100.0)$ & \multirow{2}{*}{0.044} \\
\hline Female & $416(86.3)$ & $66(13.7)$ & $482(100.0)$ & \\
\hline \multicolumn{5}{|c|}{ Age } \\
\hline $\begin{array}{l}3 \text { to } 7 \\
\text { years }\end{array}$ & $377(80.6)$ & $91(19.4)$ & $468(100.0)$ & \multirow{2}{*}{0.011} \\
\hline $\begin{array}{c}8 \text { to } 12 \\
\text { years }\end{array}$ & $518(86.3)$ & $82(13.7)$ & $600(100.0)$ & \\
\hline \multicolumn{5}{|c|}{ General health problem } \\
\hline Absent & $737(83.1)$ & $150(16.9)$ & $887(100.0)$ & \multirow{2}{*}{0.162} \\
\hline Present & $158(87.3)$ & $23(12.7)$ & $181(100.0)$ & \\
\hline \multicolumn{5}{|c|}{ Healthy tooth } \\
\hline Present & $466(97.7)$ & 11 (2.3) & $477(100.0)$ & \multirow{2}{*}{$<0.001$} \\
\hline Absent & $429(72.6)$ & $162(27.4)$ & $591(100.0)$ & \\
\hline \multicolumn{5}{|c|}{ Caries without pulp involvement } \\
\hline Present & $185(83.0)$ & $38(17.0)$ & $223(100.0)$ & \multirow{2}{*}{0.701} \\
\hline Absent & $710(84.0)$ & $135(16.0)$ & $845(100.0)$ & \\
\hline \multicolumn{5}{|c|}{ Caries with pulp involvement } \\
\hline Absent & $838(90.9)$ & $84 \quad(9.1)$ & $922(100.0)$ & \multirow{2}{*}{$<0.001$} \\
\hline Present & $57(39.0)$ & $89(61.0)$ & $146(100.0)$ & \\
\hline \multicolumn{5}{|c|}{ Restoration } \\
\hline Absent & 739 (81.9) & $163(18.1)$ & $902(100.0)$ & \multirow{2}{*}{$<0.001$} \\
\hline Present & $156(94.0)$ & $10 \quad(6.0)$ & $166(100.0)$ & \\
\hline \multicolumn{5}{|c|}{ Pulpotomy } \\
\hline Absent & 871 (84.7) & $157(15.3)$ & 1028 (100.0) & \multirow{2}{*}{$<0.001$} \\
\hline Present & $24(60.0)$ & $16(40.0)$ & $40(100.0)$ & \\
\hline \multicolumn{5}{|c|}{ Pulpectomy } \\
\hline Absent & $888(84.3)$ & 165 (15.7) & 1053 (100.0) & \multirow{2}{*}{$<0.001$} \\
\hline Present & $7(46.7)$ & 8 (53.3) & 15 (100.0) & \\
\hline
\end{tabular}

* chi-square test.

ranging from 3 to 7 years (19.4\%). Previous studies report that the persistence of untreated non-carious processes can culminate in the early loss of primary teeth, ${ }^{1,16}$ thereby affecting the eruption sequence of permanent successors. ${ }^{5,8,16,17}$ Thus, the lower prevalence of inflammatory root resorption in children 8 to 12 years of age may be attributed to possible early tooth loss prior to reaching this age. 
Table 2 - Results of the multivariate logistic regression for inflammatory root resorption.

\begin{tabular}{|c|c|c|c|c|}
\hline $\begin{array}{l}\text { Independent } \\
\text { variables }\end{array}$ & $\begin{array}{c}\text { Unadjusted } \\
\text { OR } \\
(95 \% \mathrm{Cl})\end{array}$ & $\mathrm{p}$ & $\begin{array}{c}{ }^{*} \text { Adjusted } \\
\text { OR } \\
(95 \% \mathrm{Cl})\end{array}$ & $\mathrm{p}$ \\
\hline \multicolumn{5}{|c|}{ Gender } \\
\hline Female & 1.00 & & 1.00 & \\
\hline Male & $\begin{array}{c}1.40 \\
(1.0-1.9)\end{array}$ & 0.044 & $\begin{array}{c}1.24 \\
(0.8-1.8)\end{array}$ & 0.295 \\
\hline \multicolumn{5}{|c|}{ Age } \\
\hline $\begin{array}{c}8 \text { to } 12 \\
\text { years }\end{array}$ & 1.00 & & 1.00 & \\
\hline $\begin{array}{l}3 \text { to } 7 \\
\text { years }\end{array}$ & $\begin{array}{c}1.52 \\
(1.1-2.1)\end{array}$ & $0.011 *$ & $\begin{array}{c}1.13 \\
(0.7-1.7)\end{array}$ & 0.548 \\
\hline \multicolumn{5}{|c|}{ Health problem } \\
\hline Absent & 1.00 & & 1.00 & \\
\hline Present & $\begin{array}{c}0.71 \\
(0.4-1.1)\end{array}$ & 0.163 & $\begin{array}{c}0.89 \\
(0.5-1.6)\end{array}$ & 0.705 \\
\hline \multicolumn{5}{|c|}{ Healthy tooth } \\
\hline Present & 1.00 & & 1.00 & \\
\hline Absent & $\begin{array}{c}15.99 \\
(8.5-29.8)\end{array}$ & $<0.001$ & $\begin{array}{c}8.70 \\
(4.3-17.4)\end{array}$ & $<0.001$ \\
\hline \multicolumn{5}{|c|}{ Caries with pulp involvement } \\
\hline Absent & 1.00 & & 1.00 & \\
\hline Present & $\begin{array}{c}15.57 \\
(10.4-23.2)\end{array}$ & $<0.001$ & $\begin{array}{c}7.40 \\
(4.6-11.9)\end{array}$ & $<0.001$ \\
\hline \multicolumn{5}{|c|}{ Restoration } \\
\hline Present & 1.00 & & 1.00 & \\
\hline Absent & $\begin{array}{c}3.44 \\
(1.7-6.6)\end{array}$ & $<0.001$ & $\begin{array}{c}3.15 \\
(1.5-6.6)\end{array}$ & 0.002 \\
\hline \multicolumn{5}{|c|}{ Pulpotomy } \\
\hline Absent & 1.00 & & 1.00 & \\
\hline Present & $\begin{array}{c}3.69 \\
(1.9-7.1)\end{array}$ & $<0.001$ & $\begin{array}{c}3.12 \\
(1.5-6.5)\end{array}$ & 0.002 \\
\hline \multicolumn{5}{|c|}{ Pulpectomy } \\
\hline Absent & 1.00 & & 1.00 & \\
\hline Present & $\begin{array}{c}6.15 \\
(2.2-17.1)\end{array}$ & 0.001 & $\begin{array}{c}5.40 \\
(1.8-15.8)\end{array}$ & 0.002 \\
\hline
\end{tabular}

*Adjusted for gender and age.

Pathological processes involving the hard tissues of the root (cementum and dentin) and adjacent tissues (periodontal ligament and alveolar bone) may occasionally be associated with inflammatory resorption..$^{9,18}$ Dental caries was the most prevalent pathological process in the present study. Caries with pulp involvement represented an approximate- ly sevenfold greater chance of having inflammatory root resorption. Dental pulp attacked by microorganisms that are part of the cariogenic process suffers primary inflammation/infection. ${ }^{19}$ In primary molars, this infection spreads more quickly to the inter-radicular region, owing to the lesser thickness of the pulp chamber floor and the presence of foramina in the furcation areas. As a result, bone loss occurs in the inter-radicular area, which is one of the first signs of a compromised pulp. ${ }^{10,20}$

Restorative procedures, pulpotomy and pulpectomy are among the various treatment options available for tooth decay. ${ }^{21-23}$ In the present study, the absence of a restoration and pulpotomy or pulpectomy were related to a greater occurrence of inflammatory root resorption. Pulpectomy was related to the greatest risk, with an approximately fivefold greater chance of being related to this type of root resorption. Pulpectomy is indicated for cases of advanced degenerative pulp alterations or pulp necrosis. ${ }^{24}$ According to some studies, this procedure may accelerate the process of inflammatory root resorption. ${ }^{19}$ Pulpotomy is a more conservative treatment option commonly used on teeth having deep carious lesions with no fistula or swelling, and with no periapical or furcation lesions. ${ }^{20,25}$ In the present study, however, the teeth submitted to pulpotomy were approximately threefold more likely to have a periapical lesion, a finding which agrees with that reported by Aminabadi et al., ${ }^{26}$ who found that root resorption was the second most common finding among teeth submitted to pulpotomy. Based on the abovementioned information, the occurrence of inflammatory root resorption in primary molars treated by pulpotomy or pulpectomy in the present study may be attributed to diagnostic errors made while assessing pulp condition, or to technical failure while performing the treatment chosen.

As mentioned earlier, primary molars with no restorations had an approximately threefold greater chance of displaying inflammatory root resorption. This association may be explained by the fact that some teeth had untreated caries. However, although restorative procedures are among the various treatment options available for tooth decay, ${ }^{21-23}$ the increased risk of an inflammatory resorption occur- 
ring in primary molars with no restorations should be considered with caution, since this group also included healthy teeth.

Periapical radiographs were used to assess the type of resorption in the present study. The course of a root resorption is monitored by radiographic examination only in the more advanced stages of this process, and periapical radiographs are the most commonly used diagnostic tools for this purpose. ${ }^{11,12}$ However, today there are more accurate diagnostic methods to evaluate resorption processes, including cone-beam computed tomography. ${ }^{27}$ This method is thus suggested for future investigations with the same objective as that of the present study.

One of the limitations of this study was the fact that the evaluation of radiographic images does not allow the determination of the level of caries activity or of the exact degree of pulp involvement. A study carried out by Di Nicolo et al. ${ }^{28}$ found that normal or transitioning pulp (in the treatable category) was diagnosed in $50 \%$ of teeth with inactive lesions and $11.1 \%$ of teeth with active carious lesions. Therefore, conducting a combined clinical and radiographic examination is essential to obtaining a proper diagnosis and to choosing the most appropriate treatment for each clinical situation. Another limitation of this study was that it did not allow determining the time elapsing between the completion of pulpotomy or pulpectomy and the occurrence of

\section{References}

1. Santos BZ, Bosco VL, Silva JYB, Lamb MMR. [Physiological and pathological factors and mechanisms in the process of root resorption of deciduous teeth]. RSBO (Online). 2010;7(3):3329. Portuguese.

2. Kinirons MJ, Boyd DH, Gregg TA. Inflammatory and replacement resorption in reimplanted permanent incisor teeth: a study of characteristics of 84 teeth. Endod Dent Traumatol. 1999 Dec;15(6):269-72.

3. Cardoso M, Rocha MJ. Identification of factors associated with pathological root resorption in traumatized primary teeth. Dent Traumatol. 2008 Jun;24(6):343-9.

4. Tronstad L. Root resorption - etiology, terminology and clinical manifestations. Endod Dent Traumatol. 1988 Dec;4(6):241-52.

5. Camm JH, Schuler JL. Premature eruption of the premolars. ASDC J Dent Child. 1990 Mar-Apr;57(2):128-33. inflammatory root resorption in each patient, since both events-pulp intervention and root resorption -were identified on the same radiograph at a single moment in time. Because some information was obtained through a questionnaire administered to the children's parents/caregivers, one must consider the possibility of memory bias, especially with regard to the children's medical history. Moreover, some information may have been recorded inadequately or even omitted from the clinical charts.

Because the cross-sectional design does not include temporality (exposure and outcome data are collected on a single occasion), it was not possible to determine a possible cause-effect relationship between the results. Further studies with a longitudinal design should thus be conducted to gain a better understanding of the relationship between inflammatory root resorption and the possible risk factors addressed herein.

\section{Conclusion}

The prevalence of inflammatory root resorption in the primary mandibular molars investigated in the present study was $16.2 \%$. Gender, age, an unhealthy tooth, caries with pulp involvement, pulpotomy, pulpectomy and the absence of a restoration were related to a higher occurrence of inflammatory root resorption in primary molars.

6. Gunraj MN. Dental root resorption. Oral Surg Oral Med Oral Pathol Oral Radiol Endod. 1999 Dec;88(6):647-53.

7. Sahara N. Cellular events at the onset of physiological root resorption in rabbit deciduous teeth. Anat Rec. 2001 Dec;264(4):387-96.

8. Leroy, RB. Impact of undergraduate students experience in the deciduous molars on the emergence of successors. Eur J Oral Sci 2003;111(2):106-10.

9. Fuss Z, Tsesis I, Lin S. Root resorption: diagnosis, classification and treatment choices based on simulation factors. Dent Traumatol. 2003 Aug;19(4):175-82.

10. Bolan M, Rocha MJ. Histopathologic study of physiological and pathological resorptions in human primary teeth. Oral Surg Oral Med Oral Pathol Oral Radiol Endod. 2007 Nov;104(5):680-5. 
11. Andreasen FM, Andreasen JO. Diagnosis of luxation injuries: the importance of standardized clinical, radiographic and photographic techniques in clinical investigations. Endod Dent Traumatol. 1985 Oct;1(5):160-9.

12. Sameshima GT, Asgarifar KO. Assessment of root resorption and root shape: periapical vs panoramic films. Angle Orthod. 2001 Jun;71(3):185-9.

13. Morabito A, Defabianis P. A SEM investigation on pulpalperiodontal connections in primary teeth. ASDC J Dent Child. 1992 Jan-Feb:59(1):53-7.

14. Ne RF, Witherspoon DE, Gutmann JL . Tooth resorption. Quintessence Int. 1999 Jan;30(1):9-25.

15. Borum MK, Andreasen JO. Sequelae of trauma to primary maxillary incisors. I. Complications in the primary dentition. Endod Dent Traumatol. 1998 Feb;14(1):31-44.

16. Ak G, Sepet E, Pinar A, Aren G, Turan N. Reasons for early loss of primary molars. Oral Health Prev Dent. 2005;3(2):1137.

17. Leroy R, Cecere S, Lesaffre E, Declerck D. Caries experience in primary molars and its impact on the variability in permanent tooth emergence sequences. J Dent. 2009 Nov;37(11):865-71.

18. Hammarstrom L, Lindskog S. General morphological aspects of resorption of teeth and alveolar bone. Int Endod J. 1985 Apr;18(2):93-108.

19. Nero-Vieira g. La resorción as proceso inflamatorio. Aproximación a La pathogenicity de las resorciones y dentaria periodontal. RCOE. 2005;10(5-6):545-56.
20. Kramer PF, Faraco Júnior IM, Meira R. The SEM investigation of accessory foramina in the furcation areas of primary molars. J Clin Pediatr Dent. 2003 Winter;27(2):157-61.

21. Fuks AB, Eidelman E. Pulp therapy in the primary dentition. Curr Opin Dent. 1991 Oct;1(5):556-63.

22. JOE Editorial Board . Treatment of the primary tooth: an online study guide. J Endod. 2008 May;34(5 Suppl):e107-10.

23. Blanchard S, Boynton J. Current pulp therapy options for primary teeth. J Mich Dent Assoc. 2010 Jan;92(1):38,40-1.

24. Mendoza AM, Reina JE, Garcia-Godoy F. Evolution and prognosis of necrotic primary teeth after pulpectomy. Am J Dent. 2010 Oct;23(5):265-8.

25. Souza RA, Gomes SC, Dantas JC, Silva-Sousa YT, Pécora JD. Importance of the diagnosis in the pulpotomy of immature permanent teeth. Braz Dent J. 2007;18(3):244-7.

26. Aminabadi NA, Farahani RM, Gajan EB. A clinical study of formocresol pulpotomy versus root canal therapy of vital primary incisors. J Clin Pediatr Dent. 2008 Spring;32(3):211-4.

27. D'Addazio PS, Campos CN, Özcan M, Teixeira HG, Passoni RM, Carvalho AC. A comparative study between cone-beam computed tomography and periapical radiographs in the diagnosis of simulated endodontic complications. Int Endod J. $2011 \mathrm{Mar} ; 44(3): 218-24$.

28. Di Nicolo R, Guedes-Pinto AC, Carvalho YR . Histopathology of the pulp of primary molars with active and arrested dentinal caries. J Clin Pediatr Dent. 2000 Fall;25(1):47-9. 